\title{
Is malnutrition or litchi consumption the culprit behind Acute Encephalitis Syndrome?
}

\author{
Shivashankar Kengadaran ${ }^{1}$, Anusha Divvi ${ }^{1}$, Sivabalakumaran Kengadaran ${ }^{2}$
}

AFFILIATION

1 Department of Public Heath Dentistry, Indira Gandhi Institute of Dental Sciences, Sri Balaji Vidyapeeth, Pondicherry, India

2 Department of Anaesthesiology, Government Chengalpattu Medical College, Chengalpattu, India

CORRESPONDENCE TO

Shivashankar Kengadaran. Department of Public Heath Dentistry, Indira Gandhi Institute of Dental Sciences, Sri Balaji Vidyapeeth, Pondicherry, 607402, India. E-mail: shiva.freee@gmail.com

Popul. Med. 2020;2(March):6
KEYWORDS

AES, litchi, malnourishment, infant mortality

Received: 21 February 2020, Revised: 10 March 2020, Accepted: 10 March 2020

\section{Dear Editor,}

Around 6000 children have lost their lives over the past ten years, due to outbreaks of Acute Encephalitis Syndrome (AES) in India ${ }^{1,2}$. Interestingly, all the cases were reported during May and June, which coincided with the litchi plucking season, and most of them were stunted and wasted ${ }^{3}$. Some controversies regarding causative factors of AES also need clarification. Some researchers blame litchi consumption, however, malnutrition has remained an underlying risk factor that has been largely ignored.

An outward look and decision, in this case, would adversely affect the livelihood of the farmers cultivating litchi and thereby increasing the economic burden on the country and the individual as well, which would lead to a vicious cycle of poverty and malnutrition. This critical situation demands credible scientific evidence to act upon.

An attempt has been made to find the cause using Hill's criteria. Bradford Hill proposed nine 'aspects of association' of which strength of association, consistency, and specificity are considered as fundamental tenets of causal inference in epidemiology ${ }^{4}$. The first criterion for causation is the strength of the association. Based on the data gathered, it was observed that all the children (100\%) diagnosed with AES were found to be malnourished whereas only $65 \%$ had consumed litchi, which shows that malnourishment has the highest strength of association than the latter ${ }^{1,2,5}$. However, the available studies were found to have methodological errors about the standardization of the study subjects.

Hill suggested that associations are more likely to be causal when they are consistent. Research on the Chinese population showed a lower prevalence of AES among litchi consuming children, thereby making the association between litchi and AES inconsistent ${ }^{5}$. The next criterion 'specificity' explains that causation is more likely if there is a specific outcome related to a specific exposure. When the association between malnutrition and AES was assessed, litchi consumption was a confounding factor, and malnutrition was identified as a confounding factor in the study establishing the association between litchi consumption and $\mathrm{AES}^{1,2}$. The efforts to find the relationship show that the available resources are not enough to make a conclusive association between AES, malnutrition and litchi consumption. With only four months left for the litchi harvest, this is the right time to take the necessary steps. Lack of evidence shall not be put forward as an excuse for the loss of lives.

Looking back at historic epidemic outbreaks would help us to manage these situations and prevent mortality. Knowledge gained from the experiences of Edward Jenner and John Snow shows that observational findings are enough to bring about effective prevention. Hence, measures have to be taken in improving the nutritional status of the children and the health facilities available in rural regions. Immediate steps should be taken in creating awareness among health workers in public health centers and subcenters, and they must also be trained in providing intravenous delivery of glucose if necessary, which has proven to be life-saving, as in the case of China.

\section{REFERENCES}

1. Sudhir, Kumar S, Prasad MS. Acute Encephalitis Syndrome (AES) associated with sociocultural and environmental risk factors in infants/children of Muzaffarpur, Biharhospital-based, prospective study. J Evid Based Med Healthc. 2018;5(1),23-26. doi:10.18410/jebmh/2018/5

2. Shrivastava A, Kumar A, Thomas JD, et al. Association of acute toxic encephalopathy with litchi consumption in an outbreak in Muzaffarpur, India, 2014: a casecontrol study. Lancet Glob Health. 2017;5(4):e458-e466. 
doi:10.1016/s2214-109x(17)30035-9

3. Spencer PS, Palmer VS. The enigma of litchi toxicity: an emerging health concern in southern Asia. Lancet Glob Health. 2017;5:e383-e384. doi:10.1016/s2214-109x(17)30046-3

4. Schünemann H, Hill S, Guyatt G, Akl EA, Ahmed F. The GRADE approach and Bradford Hill's criteria for causation.
J Epidemiol Community Health. 2011;65(5):392-395. doi:10.1136/jech.2010.119933

5. Zhang LJ, Fontaine RE. Lychee-associated encephalopathy in China and its reduction since 2000. Lancet Glob Health. 2017;5(9):e865. doi:10.1016/s2214-109x(17)30291-7
CONFLICTS OF INTEREST

The authors have completed and submitted the ICMJE Form for Disclosure of Potential Conflicts of Interest and none was reported.
PROVENANCE AND PEER REVIEW

Not commissioned; externally peer reviewed. 